\title{
nature
}

cell biology

\section{Science for the people}

$\mathbf{T}$

The tenth National Science week recently took place in the UK. This annual event is coordinated by the British Association for the Advancement of Science and endorsed by the UK government with the aim of publicising exciting and relevant science to foster a broad appreciation of why science is a worthy pursuit. This year over a thousand events took place across the country, attracting close to a million visitors. Commenting on the week, Prime Minister Tony Blair stated that "scientific research has never been more important or more exciting". However, is this excitement shared elsewhere in the UK and will the momentum of National Science Week inspire the next generation of researchers? We have previously discussed the implications of science teaching and the perception of scientists for future generations (see Nature Cell Biol. 3, E243). However, are there any indications that the often-innovative ideas proposed by governments and organisations such as the Howard Hughes Medical Institute are actually capturing the public's imagination or increasing the impact of science in the minds of the young?

The UK government clearly feels not: earlier this year, the Department of Education announced that the National Curriculum followed by schools would retain a compulsory science unit. Strikingly, however, this unit would no longer encompass the traditional scope of teaching basic principles of physics and biology. Instead, the proposed 'issues-based core curriculum' will focus on applied science topics more directly relevant to student's lives, such as cloning and genetically modified foods. A House of Commons Science and Technology committee reported last summer that "[current] courses are overloaded with factual content and contain little contemporary science". John Holman, who is closely associated with the development of the proposed science curriculum, comments that the course would still be fact-based, "but we should identify a relatively small number of really important scientific principles.....and concentrate on understanding them clearly". Proposed modules include 'you and your genes', 'food matters' and 'keeping healthy'. This move certainly reflects the recent emphasis of museums, such as London's Science Museum, on 'relevant research', which is hoped will capture the public imagination better. Nevertheless, there is a fundamental difference between schools, which primarily educate, and museums, which also aim to inform and to entertain. Consequently, it was not surprising that this announcement raises dissatisfaction from parts of the scientific community.

This debate is somewhat similar to that between traditionalist linguists, who vehemently oppose the Europe-wide progressive culling of Latin and Greek from national curriculi. The main argument in favour of teaching the classics is that they lay the foundation of many a European language and hence facilitate the subsequent learning of a wide spectrum of 'living' languages. On the other hand, progressive linguists argue that learning Spanish, for example, provides just as good a base for learning French thereafter and provides the considerable benefit of being able to communicate with over 50 million of our immediate European neighbours, as well as much of south America. Interestingly, recent studies support the latter viewpoint. More pragmatic commentators go further, favouring a focus beyond European languages to globally dominant ones such as Chinese.

Proponents of the applied science curriculum point to the considerable success of Science Week and science museums with applied exhibits to argue that they are on the right track to make the young more science savvy and that schools should reflect this trend. One of the best-attended science-related events to date was a recent pseudoscientific touring exhibition of plasticized anatomical specimens. Similar specimens have for years languished in numerous ill-attended anatomy department display cases, and yet here a touring exhibition attracted millions of the eager public from all walks of live. Is this a 
milestone on the path towards a better public understanding of science? For many, it will have provided the first glimpse beyond the horizon of the skin. However, the generally macabre arrangement of the specimens, supposedly reflecting artistic inspiration of their creator, probably explained the main underlying attraction better: it is likely to be more related to the considerable magnetism of the freak shows of the century before last.

So, is ensuring that the public know the Periodic Table by heart more important than a solid understanding of current scientific issues confronting society? Do students really need to know all the phyla in order to appreciate burning ecological questions? Biology is once again in the prime time news with issues including biological weapons and the 50th anniversary of the double helix. We do need to ensure that the public can understand these stories and relate to the issues being discussed. Is the perceived 'dumbing down' of science education in the UK a bad thing if it provides an appreciation of issues such as pollution, cloning and global warming? The simple answer is that an education which does indeed provide a solid understanding of all these very relevant issues has succeeded. However, a curriculum focused solely on current science-related events bypasses the prerequisite knowledge of basic principles to allow an understanding of the science in the news. It is hard to imagine how pupils will be attracted to make a career of science on this basis. Evidently, designers of curriculi should allow sufficient space in their timetables to include a well-balanced science education, providing the foundation for a scientific understanding that is essential to interpret the marvels and perils of applied science. It is critical that sufficient time is allocated to allow for a much-increased emphasis on current applications of science. However, this should not happen at the expense of a solid grounding in basic science. Just as living languages continue to draw the interest of pupils, living life-science teaching will do the same to stem the declining student numbers at universities. On the other hand, an emphasis of current facts at the expense of a basic understanding would undoubtedly accelerate the decline of science as a main career choice, with dramatic longterm consequences.

One major hurdle to overcome in making science teaching more exciting and relevant is the education of the educators, who find it increasingly challenging to keep up with the freewheeling progress of current science. The European Molecular Biology Organisation (EMBO) provides an example of a cutting-edge research institution that has attempted to address this problem: this month, EMBO will run their second international practical workshop for science teachers. This workshop is themed around the revolution in biological research since the discovery of the structure of DNA. Encouraging science teachers to come together and discuss science not only with one another, but also with leading researchers in the field, will surely mean that the excitement of science is taken back to every classroom. We all realise that as scientists we have a responsibility to ensure the public understand the implications of scientific research and discoveries. Numerous other successful projects, such as the experiments carried out by pupils from Europe, Japan and North America on the doomed final Columbia mission (see Nature 421, 307 (2003) and Nature 421, 562 (2003)) and the molecular modelling work carried out by high school students in Wisconsin as part of "Team Anthrax" (see Nature 420, 12 (2003) attest to a real shift in appreciation of the need to bring pupils themselves closer to the science. 